\title{
Research on Contract Management for the Urban Rail Transport BOT Project
}

\author{
Weifang Li \\ School of Management, Wuhan University of Science and Technology, Wuhan City, Hubei \\ Province, 430081 \\ wustlwf@163.com
}

\begin{abstract}
BOT is abbreviated from Build- Operate-Transfer model, as a new kind of investment and financial measure, which is applied to urban rail transport construction. It can reduce difficulty in capital and workload of coordination and management as well as increase the performance efficiency of urban rail transit and serve as finance-resistance role in view of government. As for the contractor of BOT project, it not only extends market scale but motivates the innovation in running method, concepts and management modes. First of all, this thesis expounds the operation modes and management-related basic foundations on contracts, and then analyzes main manners and contests of contract management for urban rail transit BOT project, as well as its current researches and other problems in China. On this basis, it puts forward solutions to improve urban rail transit BOT project, including urban rail transit BOT project's contract structure planing, coordination, contract assessment, management on contract fulfillment etc.
\end{abstract}

Keywords: Urban rail transit; BOT project; Contract structure planing; Contract assessment

\section{城市轨道交通 BOT 项目合同管理研究}

\author{
李维芳 \\ 武汉科技大学管理学院, 湖北省 武汉市 430081
}

摘要: BOT (Build- Operate-Transfer) 即“建设-运营-移交”模式作为一种新的投融资方式应用到城市轨道交通项目, 对 政府而言，可缓解资金困难、减少协调与管理工作量、提高城市轨道交通运作效率及防范金融风险; 对 BOT 项目承办人而 言, 不仅可扩大市场占有规模, 更促进了经营方式、理念与管理模式的创新。本文首先阐述了城市轨道交通 BOT 项目运作 模式及合同管理相关理论基础, 然后分析了城市轨道交通 BOT 项目合同管理主要形式与内容、我国当前城市轨道交通 BOT 项目合同管理现状及有关问题。在此基础之上，提出了完善城市轨道交通 BOT 项目合同管理的若干对策，包括在城 市轨道交通 BOT 项目合同体系策划及协调、项目合同评估、合同履约管理等方面的有关对策。

关键词: 城市轨道交通; BOT 项目; 合同体系策划; 合同评估

引言

目前, 我国城市轨道交通建设发展迅速, 且日渐趋成为我国城市现代化的重要影响因素, 然由于经 营效率低，若只靠政府的财政投入和国债等传统的资金募集方式，则无法满足城市现代化建设的需求。 因此, 近年来建设一运营一移交 (Build-Operate-Transfer, 简称 BOT) 融资模式以其强大的融资建设功能 在国内引起广泛关注, 并在一些大型基础设施建设项目中成功运作。然而 BOT 模式在我国城市轨道交通实 施过程中依然有不少问题, 至今国内还没有其统一的相关合同标准和建设规范。许多 BOT 项目承办人在 在投资建设过程中遇到合同管理和实施困难。因此研究城市轨道交通 BOT 项目合同管理存在问题及对策 相结合, 有利于城市轨道交通 BOT 项目的顺利实施。 


\section{1 城市轨道交通 BOT 项目合同管理理论基础}

\section{1 城市轨道交通内涵}

在中国国家标准《城市轨道交通常用名词术语》中, 对城市轨道交通的定义为: “通常以电能为动 力, 采取轮轨运输方式的快速大运量公共交通的总称”。 ${ }^{[2]}$

美国工程学会 ASTM 对城市轨道交通的定义是：城市轨道交通 (Unban rapid rail transit) 是指利用 地面、地下或高架设施, 不受其他地面交通干扰, 使用专用动力车辆行驶于专用路线, 并以密集班次, 大量快速输送城市与近邻地区旅客的公共运输系统。

\subsection{BOT 模式的内涵}

BOT (Build-Operate一Transfer), 即建设一经营一转让, 又称基础设施特许权。是指政府为了完成 某项基础设施建设项目, 通过与私营企业达成协议, 允许其融资建设并在一定时期内经营和管理该项 目, 通过收取服务费用或出售产品来回收投资并赚取利润。特许期结束时, 私营企业要按合同的约定将 项目的经营和管理权移交给政府部门 ${ }^{[3]}$ 。其实质是政府通过出让基础设施特许经营权的方式, 将民间资本 引入到基本设施建设领域，以缓解财政资金压力。

\section{2 城市轨道交通 BOT 项目合同体系、合同管理内容及现状}

\section{1 城市轨道交通 BOT 项目运作模式及合同体系}

城市轨道 BOT 项目的实施需要进行 BOT 项目前期准备阶段、BOT 项目招商洽谈阶段、BOT 项目招投标 阶段、BOT 合同签订阶段和 BOT 项目融资建设阶段、BOT 项目运营及移交阶段。在城市轨道交通 BOT 项目 运作过程中全程参与者有政府部门、招商部门、建设主管部门、BOT 项目发起人、BOT 项目承办人等, 从 BOT 项目准备阶段至 BOT 投资建设合同签订完成的全部工作都落实到《项目框架协议书》和《BOT 项目合 同书》合同文件 ${ }^{[4]}$ 。城市轨道交通 BOT 项目合同选择和确定流程如图 1 。

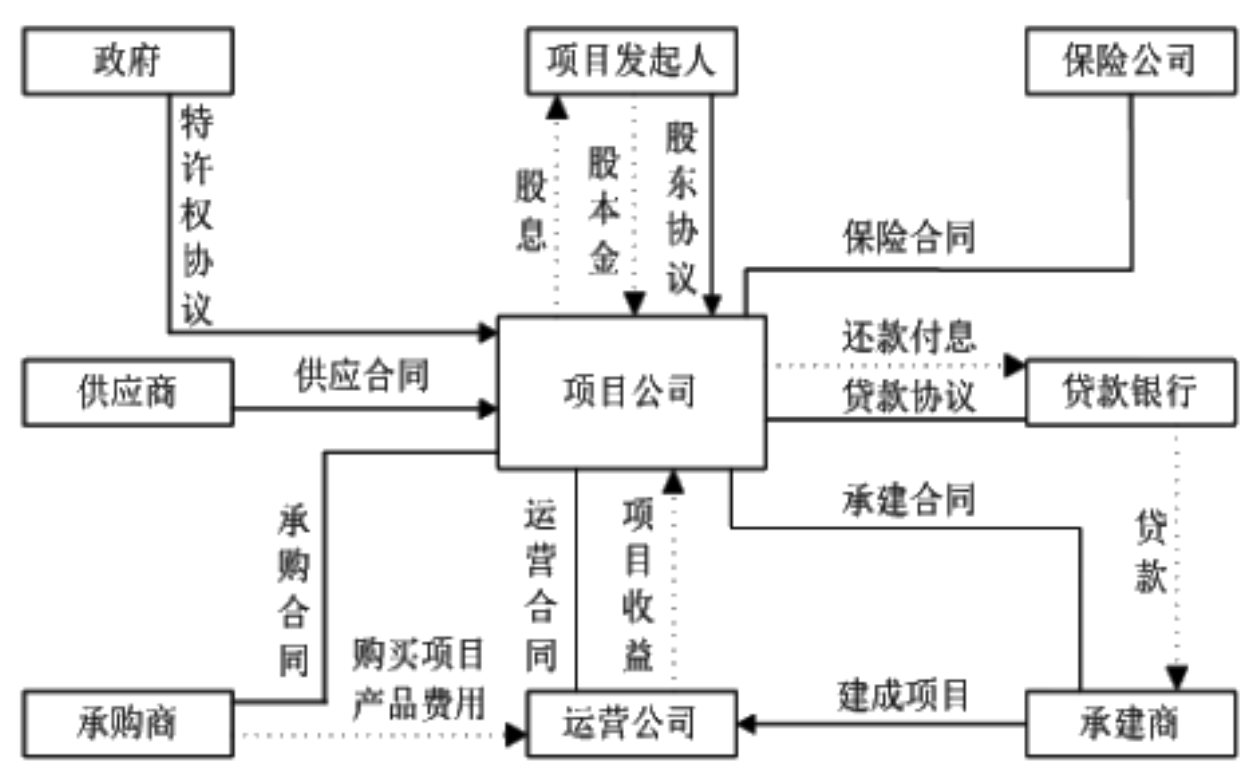

图 1 BOT 项目运作流程及合同体系

\section{2 城市轨道交通 BOT 项目合同管理内容}

至今我国关于城市轨道交通 BOT 项目合同没有统一的合同格式，BOT 项目发起人和 BOT 项目承办人主 
要根据《合同法》、《建筑法》、《招投标法》等法规, 遵循公平、公正、诚信等基本原则进行设计拟 定。城市轨道交通 BOT 项目投资建设合同的内容必须涵盖：项目的施工范围、BOT 投资建设合同价格与回 购付款、项目的施工期限、项目的工程质量、BOT 项目承办人和 BOT 项目发起人的权利和义务、项目的融 资建设管理、项目材料设备供应问题、施工标准、项目的竣工验收、项目保险、项目运营期限、项目收 费及支付补贴、项目移交等条款。城市轨道交通 BOT 项目发起人和 BOT 项目承办人根据以上基本内容完 成 BOT 投资建设合同的设计、谈判、签署及履约。

\section{3 城市轨道交通 BOT 项目合同管理现状及问题}

(1) 城市轨道交通 BOT 项目合同在履行期内缺乏有效监管。一部分城市轨道交通 BOT 项目工作人员 并不清楚城市轨道交通 BOT 项目每个阶段实施的内容、过程和应该达到的质量标准，根据城市轨道交通 BOT 合同规定无法对 BOT 项目实施过程进行有效监控。

(2) 城市轨道交通 BOT 合同相关部门把控不严。少数部门在 BOT 合同管理方面缺乏经验, 也没有完 善的管理制度, 同时对于 BOT 合同审查把控缺少力度。城市轨道交通 BOT 项目合同签订过程也不够规 范, 缺少相关法律规定, 对于 BOT 合同实施过程中违约现象没有做出明确规定; 签订的城市轨道 BOT 项 目的合同内容过于单一，相关条款不够明确，对于责、权、利的划分也不够明确。

\section{3 完善城市轨道交通 BOT 项目合同管理若干对策}

\section{1 注重城市轨道交通 BOT 项目合同体系策划及协调}

城市轨道交通 BOT 项目合同体系策划是根据 WBS 分解出建设期限内施工内容的全部工作，然后根据 BOT 项目发起人确定的城市轨道交通 BOT 项目的运作模式对 BOT 合同承包范围进行初步划分, 构成城市轨 道交通 BOT 项目的合同体系 ${ }^{[5]}$ 。城市轨道交通 BOT 项目合同体系策划要应该做到城市轨道交通 BOT 项目施 工内容落实到各个合同中，尽量不要有缺漏、重复等情况。城市轨道交通项目合同体系策划时应重点考 虑以下因素: 城市轨道交通 BOT 项目的特点、BOT 项目发起人对城市轨道交通 BOT 项目的要求、BOT 项目 发起人管理城市轨道交通 BOT 项目的能力、BOT 项目承办人的施工水平等。

在城市轨道交通 BOT 项目中需要签订一系列的 BOT 合同，在其合同体系中，相同级别的 BOT 合同之 间, 以及总包合同和分包合同之间有着错综复杂的关系, 形成一个繁琐的合同网络。城市轨道交通 BOT 项目的合同体系应确保涵盖城市轨道交通工程建设的全部内容。城市轨道交通 BOT 项目合同体系间的协 调包括以下内容：时间上的协调、价格上的协调、技术上的协调、组织上的协调。

\section{2 完善城市轨道 BOT 项目合同签订管理}

\section{2.1 注重合同评估}

城市轨道交通 BOT 项目合同条件评估是合同准备和谈判签订前的核心工作，主要从以下几个方面进 行。

（1）城市轨道交通 BOT 项目的基本条件。城市轨道交通 BOT 项目的准备阶段有关立项、批文、授权 手续是否完善; 城市轨道交通 BOT 项目设计进展情况、项目的征地拆迁进度及资金的来源等都很重要。

（2）城市轨道交通 BOT 项目的施工期限和质量要求。基于城市轨道交通工程的实际情况包括征地拆 迁进度、建设施工时有无干扰、材料设备是否及时供应等情况, 合理评估城市轨道交通 BOT 项目的施工 进度, 以此作为确定城市轨道交通 BOT 项目融资方案和资金投入计划的重要参考因素, 从而保证城市轨 
道交通 BOT 项目的有序进行。

（3）城市轨道交通 BOT 项目的验收。只有完成 BOT 项目投资建设合同的全部工作内容并通过监理单 位和 BOT 项目发起人的验收后, 才能进入项目转让运营阶段。因此对于城市轨道交通工程竣工验收的流 程具体条款须予以明确。

（4）城市轨道交通项目的运营。明确项目运营的责任主体、运营期限、同时应根据项目的建设成 本、运营成本、利润水平等情况明确运营项目的收费标准、政府运营补贴支出及渠道、配套投入等内 容。

（5）城市轨道交通 BOT 项目合同的移交。项目合同中应明确约定移交形式、补偿方式、移交内容和 移交标准。移交形式包括期满终止移交和提前终止移交; 补偿方式包括无偿移交和有偿移交; 移交内容 包括项目资产、人员、文档和知识产权等; 移交标准包括设备完好率和最短可使用年限等指标。采用有 偿移交的, 项目合同中应明确约定补偿方案 ${ }^{[6]}$ 。

\section{2.2 BOT 项目洽商与合同拟定}

城市轨道交通 BOT 投资建设合同洽商是 BOT 投资建设合同签定的准备工作。目前我国部分城市对相 关专业技术、管理人才和实践经验等工作依然需进一步加强完善，对有关的建设规范和合同管理方面不 够了解。因此 BOT 合同谈判期间 BOT 项目发起人和 BOT 项目承办人需作好充分的交流和取证，以免发生 合同双方意见、目标出现偏差等情况, 导致城市轨道交通 BOT 项目洽商的失败。

在城市轨道交通 BOT 合同展开洽商前, BOT 项目承办人需对城市轨道交通 BOT 项目合同文件进行初步 草拟。为了确保城市轨道交通 BOT 项目运作过程的连续性, 合同草拟与合同评审的相关工作成员尽可能 和城市轨道交通 BOT 项目团队成员保持一致并同时进行。在完成以上所有工作后, 就进入合同签订阶 段。紧接着合同管理的下一步工作到 BOT 项目融资建设阶段即合同的履约阶段。

\section{3 加强 BOT 项目投资建设合同履约过程管理}

在运作过程中, 一方面, 为确保城市轨道交通 BOT 合同相关条款落实到位, 减少城市轨道交通 BOT 项目合同管理漏洞，降低城市轨道交通 BOT 项目风险在合同需要在 BOT 投资建设合同履约过程中的做好 合同规范化管理，城市轨道交通 BOT 项目履约过程规范管理要做好以下几点： BOT 投资建设合同交底工 作的管理；实行城市轨道交通 BOT 合同模块化管理、落实 BOT 投资建设合同履约过程中各参与主体责 任；BOT 投资建设合同履约过程中的登记管理制度；城市轨道交通 BOT 项目合同履行的后评估制度。另一 方面, 做好城市轨道交通 BOT 项目合同实施管理也必不可少, BOT 项目合同实施管理的重点主要有: 合理 定位 BOT 投资合同履约过程中合同主体角色、BOT 投资建设合同履约的时限性管理、BOT 投资建设合同履 约过程的工程变更管理 ${ }^{[7]}$ 。

\section{4 结语}

在我国城市轨道交通项目建设中，BOT 模式不断得到应用，但是关于其运作模式和合同管理方面的问 题依然需要进一步探索。希望有更多的专家参与到城市轨道交通 BOT 项目管理研究, 为政府进一步完善 城市轨道交通 BOT 项目运行模式和合同管理相关政策提供有力支持。

\section{参考文献:}

［1］陆悟深. 城市轨道交通 BT 模式探讨 $[J]$ 。现代商贸工业，2011，（19）:1-2 
[2] 陈东月，马瑞言. 中国城市轨道交通的发展与展望 $[J]$.才智，2013，（4）：15-18

[3] 贺霞. 基础设施建设项目 BOT 与 BT 模式的比较研究 $[\mathrm{J}]$. 湖南财政经济学院学报, 2013，10(5)：59-62

[4] 丁晓欣. 建设工程合同管理 $[\mathrm{M}]$. 北京：清华大学出版社，2015

[5] 袁凤薇. 城市轨道交通项目 RB 合同体系 $[J]$. 研究管理天地，2010，(8):1-3

[6] 苏国亮. BT 模式下工程施工企业的合同与建设管理 [D]. 武汉工程大学硕士学位论文. 2013. 13-47

[7] 吴好生, 宓卫东. 宁波城市轨道交通项目合同管理探析 [J]. 论坛园地, 2012, (6) : 1-4

\section{References:}

[1] Lu Wushen. Studies on Urban Rail Transit BT Mode [J].Modern Business Trade Industry,2011,(19):1-2

[2] Chen Dongyue, Ma Ruiyan. Development and Prospect on China's Urban Rail Transit [J]. Intelligence, 2003, (4):15-18

[3] Hexia. Comparative Studies on Infrastructure BOT Project and BT Mode [J]. Journal of Hunan Finance and Economics University,2013,10(5):59-62

[4] Ding Xiaoxing. Management on Building and Engineering Contract [M].Beijing: Tsinghua University Press, 2015.

[5] Yuan Fengwei. RB Contract Restructure on Urban Rail Transit Project [J].Study Management Forum, 2010, (8):1-3

[6] Su Guoliang. Engineering Construction Enterprise's Contract and Management Based on BT Mode [D]. Master Degree Thesis of Wuhan Engineering University, 2013-13-47.

[7] Wu Haosheng, Mi Weidong. Exploration on Contract Management for Urban Rail Transport Project in Ningbo City [J].BBS Forum,2012,(6):1-4 